\title{
Patterns of change in $\alpha$ and $\beta$ taxonomic and phylogenetic diversity in the secondary succession of semi-natural grasslands in the Northern Apennines
}

\author{
Lorenzo Lazzaro ${ }^{\text {Corresp., } 1}{ }$, Lorenzo Lastrucci ${ }^{2}$, Daniele Viciani ${ }^{1}$, Renato Benesperi ${ }^{1}$, Vincenzo Gonnelli $^{3}$, Andrea \\ Coppi $^{1}$ \\ ${ }^{1}$ Department of Biology, University of Florence, Florence, Italy \\ 2 Natural History Museum, Botany, University of Florence, Florence, Italy \\ 3 Unaffiliated, Pieve S. Stefano, Italy \\ Corresponding Author: Lorenzo Lazzaro \\ Email address: Iorenzo.lazzaro@unifi.it
}

We studied the secondary succession in semi-natural grasslands (dry grasslands and hay meadows) located in the eastern side of the Tuscan Apennines (Tuscany, Central Italy). We compared these habitats, investigating: i) the changes in species richness, composition and phylogenetic diversity during the succession; ii) whether the trends in species loss and species turnover in taxonomic diversity matched those in phylogenetic diversity. We performed a stratified random sampling, in a full factorial design between habitat type and succession stage (60 sampled plots, $10 \times 2$ types of habitat $\times 3$ stages of succession). We constructed a phylogenetic tree of the plant communities and compared the differences in taxonomic/phylogenetic $\alpha$ - and $\beta$-diversity between these two habitats and during their succession. We identified indicator species for each succession stage and habitat. Looking at $\alpha$-diversity, both habitats displayed a decrease in species richness, with a random process of species selection in the earlier succession stages from the species regional pool. Nevertheless, in the latter stage of dry grasslands we recorded a shift towards phylogenetic overdispersion at the higher-level groups in the phylogenetic tree. In both habitats, while the richness decreased with succession stage, most species were replaced during the succession. However, the hay meadows were characterized by a higher rate of new species' ingression whereas the dry grasslands became dominated with $\mathrm{J}$. communis. Accordingly, the two habitats showed similar features in phylogenetic $\beta$-diversity. True phylogenetic turnover resulted the main component, due to replacement of unique lineages along the succession. Nevertheless, in dry grasslands this trend is slightly higher than expected considering the major importance of difference in species richness of dry grasslands sites, and this is due to the presence of a phylogenetically very distant species (V. communis). 
1 Patterns of change in $\alpha$ and $\beta$ taxonomic and phylogenetic diversity in the secondary

2 succession of semi-natural grasslands in the Northern Apennines

3

4

5

6

7

8

Lorenzo Lazzaro ${ }^{1}$, Lorenzo Lastrucci ${ }^{2}$, Daniele Viciani ${ }^{1}$, Renato Benesperi ${ }^{1}$, Vincenzo Gonnelli ${ }^{3}$ \& Andrea Coppi ${ }^{1}$

${ }^{1}$ Department of Biology, University of Florence, Via G. La Pira 4, 50121 Florence, Italy; ${ }^{2}$ Natural History Museum, Botany, University of Florence, Via G. La Pira 4, 50121 Florence, Italy; ${ }^{3}$ Via Martiri della Libertà 1, 52036 Pieve S. Stefano, Italy.

Corresponding Author:

Lorenzo Lazzaro ${ }^{1}$

${ }^{1}$ Department of Biology, University of Florence, Via G. La Pira 4, 50121 Florence, Italy; Email address: lorenzo.lazzaro@unifi.it

\section{Abstract}

We studied the secondary succession in semi-natural grasslands (dry grasslands and hay meadows) located in the eastern side of the Tuscan Apennines (Tuscany, Central Italy). We compared these habitats, investigating: i) the changes in species richness, composition and phylogenetic diversity during the succession; ii) whether the trends in species loss and species turnover in taxonomic diversity matched those in phylogenetic diversity. We performed a stratified random sampling, in a full factorial design between habitat type and succession stage ( 60 sampled plots, $10 \times 2$ types of habitat $\times 3$ stages of succession). We constructed a phylogenetic tree of the plant communities and compared the differences in taxonomic/phylogenetic $\alpha$ - and $\beta$-diversity between these two habitats and during their succession. We identified indicator species for each succession stage and habitat. Looking at $\alpha$ diversity, both habitats displayed a decrease in species richness, with a random process of species selection in the earlier succession stages from the species regional pool. Nevertheless, in the latter stage of dry grasslands we recorded a shift towards phylogenetic overdispersion at the higher-level groups in the phylogenetic tree. In both habitats, while the richness decreased with succession stage, most species were replaced during the succession. However, the hay meadows were characterized by a higher rate of new species' ingression whereas the dry grasslands became dominated with J. communis. Accordingly, the two habitats showed similar features in phylogenetic $\beta$-diversity. True phylogenetic turnover resulted the main component, due to replacement of unique lineages along the succession. Nevertheless, in dry grasslands this trend is slightly higher than expected considering the major importance of difference in species richness of dry grasslands sites, and this is due to the presence of a phylogenetically very distant species (J. communis).

Peer] reviewing PDF | (2019:07:39774:3:0:NEW 28 Jan 2020) 


\section{Introduction}

42 Secondary semi-natural grasslands represent important components of European cultural 43 landscapes. They derive from centuries of traditional land use, mainly linked to grazing by

44 livestock (pastures) or hay-making (meadows) (Dengler et al. 2014; Janišová et al. 2011). Many

45 secondary grassland vegetation types are considered habitats worthy of conservation and are 46 listed in European and national protection directives and laws, such as the Low altitude hay 47 meadows and the Festuco-Brometea dry grasslands (respectively codes 6510 and 6210 , 48 according to European Council Directive 92/43/EEC). In Europe, because of recent cultural 49 changes, secondary grasslands and meadows have displayed an overall tendency to evolve into 50 shrublands and woodlands through natural secondary successions (Dengler et al. 2014; Monteiro 51 et al. 2011; Peco et al. 2006; Peco et al. 2012). Perennial grasslands undergo a vegetation 52 dynamism leading to the gradual transition from herbaceous coenoses belonging to 53 syntaxonomical classes such as Festuco-Brometea or Molinio-Arrhenatheretea (e.g. Allegrezza 54 and Biondi, 2011; Biondi et al. 1995) to shrub coenoses belonging, especially in central Italy, mainly to the Rhamno-Prunetea class (e.g. Biondi et al. 1988). The shrubland formations are sometimes preceded by intermediate phases dominated by other herbaceous species such as Brachypodium rupestre (Assini et al. 2014) and mostly originate from the species that form the fringes of woods surrounding grasslands (Biondi et al. 1988; Poldini et al. 2002).

Such succession, with the consequent loss in species, has been widely studied from a landscape viewpoint (Bracchetti et al. 2012; Rocchini et al. 2006; Viciani et al. 2018). Many authors have also focused on the functionality of the communities, elucidating the central role of competition in the loss of species characterizing the early phases of succession (Csergö et al. 2013; Lepš 1999; Peco et al. 2012). Nevertheless, less is known regarding the changes occurring in the communities with respect to trends in $\beta$-diversity phylogenetic relationships, also concerning their link with changes at the taxonomic level. Indeed, according to Chase and Myers (2011), $\beta$ -

66

67

68

69

70

71

72

73

74

75

76

77

78

79

80 diversity can provide considerable insights into the importance of deterministic and stochastic processes in generating community structure along spatial and ecological gradients. In addition, the use of molecular phylogenies may be helpful in analyzing the forces that influence patterns of biodiversity and biogeography, and in depicting the interactions among co-occurring species (Selvi et al. 2016). Indeed, in the last decades, the use of molecular phylogeny has increased widely for ecological purposes, contributing also to the emerging area of community phylogenetics (Webb et al. 2002). One of the multiple ways to use the phylogenetic information consists in the measure of the phylogenetic overdispersion or clustering of the community in relation to the variation of the habitat conditions (Erickson et al. 2014; Qian et al. 2014; Selvi et al. 2016). Recently, many authors (Webb 2000; Webb et al. 2002; Kembel 2009) have highlighted that the observed patterns of phylogenetic structure of the communities could be used to understand the processes of community assembly, particularly linking patterns of phylogenetic clustering and overdispersion with the processes of habitat filtering and competitive exclusion. Indeed, the use of phylogenetic patterns as proxies for the processes of community assembly is rapidly raising concerns linked to the assumptions underlying such approach, often 
81 only weakly supported. In particular, these assumptions regard the existence of an actual 82 correlation between measures of phylogenetic dispersion and trait dispersion, the idea that trait 83 similarity would enhance competition and that competition necessarily causes species exclusion 84 from the community, and that community assemblages are in status of equilibrium (see Gerhold 85 et al. 2015; Prinzing 2016). Furthermore, Kraft et al. (2015) reported a misuse of the concept of 86 environmental filtering, considering that most empirical studies hardly distinguish the effects of 87 abiotic factors from those of biotic interactions, and often overestimate the role of the 88 environment in shaping communities.

89 In our study area, the Tuscan Apennines, the co-occurrence of initial species in secondary 90 grasslands is driven by different agricultural management in different geo-morphological 91 conditions. The areas with low slope inclination and relatively fertile and deep soils are at first 92 subjected to machining and sowing, mainly with plants that increase the nutrient value in the soil 93 (i.e. Medicago sativa, Onobrychis viciifolia). Then, herbaceous natural grassland species (many 94 from the families Poaceae, Fabaceae and Asteraceae) start to colonize these communities,

95 96 97 98 99 which in a few years become semi-natural hay meadows (Ubaldi 2003). On the other hand, areas on steeper slopes with shallow (sometime even rocky) soils are used as pastures and become dry grasslands. Also in our area of study, the main characteristic differentiating the two habitat types is the stand geomorphology, with significantly steep dry grasslands and almost flat hay meadows: these differences may affect the water capacity, structure and fertility of soils. We expect that these ecological differences may also affect the secondary succession, leading to different species assemblages. Indeed, as anthropic pressures are relieved, the succession of these habitats is generally characterized by intermediate phases dominated by herbaceous species, leading finally to quite different shrub formations. In particular, while shrubland following hay meadows are dominated by several species of broadleaf shrubs, dry grasslands are dominated by Juniperus communis, a distantly related stress-tolerant species (Pierce et al. 2017).

The study of taxonomic, phylogenetic and functional plant ( $\alpha$ and $\beta$ ) diversity along secondary succession has already been the object of studies (see Purscke et al. 2018), which highlighted that the relative importance of assembly processes had changed over time, but with contrasting patterns of temporal change in the different facets of diversity. Nevertheless, while Purscke et al. (2013) observed a general increase in taxonomic, phylogenetic and functional alpha-diversity during succession, we expect a decrease in species taxonomic diversity, not necessarily linked to a decrease in phylogenetic diversity. Moreover, Purscke et al. (2013) reported a predominant role of abiotic filtering in community assembly during the early stages of grassland succession, whereas the relative importance of competitive exclusion appears to have increased towards the later succession stage. Conversely, a major role of competition by dominant tall grasses as already been described for the early stages of succession in Apennine grasslands communities (Corazza et al., 2016). According to these differences, we sought to i) assess the relative changes in $\alpha$ - and $\beta$-diversity taxonomic and phylogenetic diversity, also identifying the indicator species in the different stages of the succession and ii) assess whether the trends in species loss and species turnover in taxonomic diversity matches those in phylogenetic diversity. Moreover, we 
121 further hypothesize that Juniperus communis may have a pivotal role, driving a certain degree of

122 overdispersion of the phylogenetic structure of the communities in dry grasslands, considering its

123 distant relatedness.

124 Toward these aims, we conducted a sampling of dry grasslands and hay meadows plant

125 communities in the Tuscan Apennines, adopting a chrono-sequential approach to reconstruct

126 their dynamic changes, assessing the changes in of $\alpha$ - and $\beta$-diversity within and between three

127 succession stages of these two habitats.

128

129

\section{Materials \& Methods}

130

131

132

133

134

\section{Study area}

The study area is located in the Adriatic side of the south-eastern Tuscan Apennines (Tuscany, Central Italy, $43.691838^{\circ} \mathrm{N} 12.111936^{\circ} \mathrm{E}$ ). The area is managed by the Raggruppamento

135 Carabinieri Biodiversità of the Reparto Carabinieri Biodiversità Pieve Santo Stefano. The most represented geological units are the clays of the Sillano Formation, deposits of landslide debris

137 and, to a lesser extent, the sandstones of Falterona Mount (Carmignani et al. 2013). Climate

138

139 belongs to the Temperate Oceanic Bioclimate (Pesaresi et al. 2017).

\section{Sampling design}

141

The study was carried out exploiting a random/stratified sampling design involving two layers: type of habitat (hereafter Habitat) and stage of succession (hereafter Succession). To identify and map these layers correctly, we performed an analysis of orthophotos of the study area using the QGis software (version 2.14.21, QGIS.ORG project). We used the cover percentage of scrub to distinguish: i) dry grasslands and hay meadows (shrub presence not detectable), ii) mixed typologies (dry grasslands/hay meadows with shrub cover $<50 \%$ ) and iii) shrubland (shrub cover $>50 \%$ ). Using also the historical knowledge concerning the landscape management provided by the local administrator, we defined the sampling layers as follow: 1) Habitat (corresponding to the land use) distinguishing between dry grasslands and hay meadows and 2) Succession, distinguishing between i) active (hereafter Managed) ii) short-time abandoned (hereafter Transition) and iii) long-time abandoned areas (hereafter Abandoned). The stage of succession is used as a proxy for the time from abandonment of the typical land management practices, considering that an increase of the cover of shrubs corresponds to the increase of time following abandonment. Hence, we performed a random selection of 10 square plots of $2 \times 2$ meters for each stratum in a full factorial design, leading to 60 sampled plots $(10 \times 2$ types of habitat $\mathrm{x} 3$ stages of succession). In each plot, we performed a floristic sampling, recording the presence/absence of vascular plants. Voucher specimens were collected for identification in the laboratory, and further samples were collected for the genetic analyses. 
160 Phylogenetic diversity of the spermatophyte communities was inferred from the analysis of three

161

162

163

164

165

166

167

168

169

170

171

172

173

174

175

176

177

178

179

180

181

182

183

184

185

186

187

188

189

190

191

192

193

194

195

196

197

198 markers of the nuclear ribosomal DNA, the ITS1-5.8S and ITS2 regions. These markers, widely used for phylogenetic studies both in plants and fungi, have shown a great discriminatory power at low taxonomic levels (Feliner and Rosselló 2007; Hollingsworth et al. 2011), supporting this region as a core barcode for spermatophytes ( $\mathrm{Li}$ et al. 2011) and hence potentially usable as a proxy for evolutionary relationships. We assembled a sequence dataset by retrieving accessions of the sampled species from GenBank (http:/www.ncbi.nlm.nih.gov/) to construct a tree resolved at the species level. Molecular analyses were performed for 13 species for which no accessions were available in the GenBank. Isolation of genomic DNA followed a modified $2 \times$ CTAB protocol successfully adopted in previous studies using molecular tools (see Coppi et al. 2008 and Appendix S1 for further details).

The final dataset of the sampled species consisted of 147 accessions (Table S2). Taxa from Gnetales, Ginkgoales, Cycadales, Pinales and Cupressales were added in order to obtain a correct alignment for Gymnosperms, whereas four taxa from Polypodiales and Salviniales were added as outgroups (Table S1). Multiple alignment of the ITS-5.8S dataset was performed with MAFFT (v. 7.0, Katoh and Standley 2013) adopting the parameterization typically used for nucleotide sequences $(200 \mathrm{PAM} / \mathrm{k}=2$, gap penalty $=1.53$; offset $=0.0)$, considering that we aligned very distant species. We followed a step by step multi-alignment procedure: (1) taxa were grouped at the order level and aligned using the Q-INS-i strategy, checking each multi-alignment by visual inspection with BioEdit; (2) the multi-alignments were merged at higher ranks using the merge option in MAFFT, obtaining separate multi-alignments for Eudicots, Monocots, Gymnosperms and for the outgroup; (3) these four multi-alignments were finally merged again. The alignment was used to build a phylogenetic tree with a maximum likelihood (ML) approach by means of RAxML (Stamatakis, 2006) via the CIPRES supercomputer cluster (http://www.phylo.org/), using 1000 maximum searches. The topology of phylogenetic inference was constrained at the family level using as backbone the tree slik2015 (Slik et al. 2018) available in Phylomatic vers. 3 (http://phylodiversity.net/phylomatic/). This topology is mainly based on the APG III phylogeny, further resolved up to genus level using the species-level phylogeny in Zanne et al. (2014), placing at the base of their respective families genera not present in Zanne et al. (2014), see Slik et al. (2018). The resulting topology is highly consistent with the hypothesis in Magallón et al. (2015), which was subsequently used to date the phylogeny, except for the clade involving the Malpighiales and the one involving Boraginales, Solanales, and Gentianales. For these clades we followed the tree slik2015. The statistical support to the nodes was estimated using the bootstrap method (1000 iterations). Finally, to obtain an ultrametric tree, we calibrated our phylogeny dating the node ages according to Magallón et al. (2015), adopting a Molecular Dating approach throughout Penalised Likelihood estimation via the chronos function of ape v5.1 R package (Paradis et al. 2004).

\section{Evaluation of trends in species richness and phylogenetic relatedness ( $\alpha$-diversity)}

Peer] reviewing PDF | (2019:07:39774:3:0:NEW 28 Jan 2020) 
199 We evaluated the changes in taxonomic species richness (SR) and in three indices allowing the 200 assessment of different features of phylogenetic $\alpha$-diversity. We used the Phylogenetic Diversity 201 (PD) as a measure of the amount of phylogenetic richness in the communities (how much) and 202 the Net Relatedness Index (NRI) and the Nearest Taxon Index (NTI) to provide information 203 regarding the phylogenetic divergence within the communities (how different they are) (see 204 Tucker et al. 2017).

205 Faith's PD (Faith 1992) represents the simplest measure of the cumulative evolutionary age in a 206 community, but it is highly correlated to species richness. Thus, we adopted its Standardized

207

208

209

210

211

212

213

214

215

216

217

218

219

220

221

222

223

224

225

226

227

228

229

230

231

232

233

234

235

236

237

238

Effect Size index that is generally considered unaffected by species richness (Pavoine et al. 2013; Swenson 2014; but see Sandel 2018), and indicates whether the observed PD is different from what would be expected by chance. To allow an interpretation of results comparable with NRI and NTI, we multiplied PD.ses by -1 . We defined NTI and NRI as Standardized Effect Size indices of Mean Nearest Taxon Distance (MNTD) for taxa in a community and Mean Pairwise Distance separating taxa in a community (MPD). MNTD is calculated as the mean of the smallest non-diagonal value in the pairwise distance matrix for each species and is a measure of the branch-tip phylogenetic clustering of the species in the community (Webb et al. 2002). It describes the phylogenetic relatedness among species, focusing on the distal part of the tree, thus involving lower taxonomical levels. MPD estimates the average phylogenetic relatedness between all possible pairs of taxa in an assemblage, calculated as the mean of the non-diagonal elements in the pairwise distance matrix (Webb 2000). It is a measure of the relationship at the higher-level groups in the phylogenetic tree. NTI and NRI indicate whether the values of MPD and MNTD differ from what would be expected by chance. Positive values of NRI and NTI indicate that observed phylogenetic distances are lower than expected and that phylogenetic clustering of species occurs. Conversely, negative values of such indices indicate phylogenetic over-dispersion or evenness. In general terms, NTI and NRI values higher/lower than 1.96/-1.96 are usually considered indicators of significant patterns. All standardized indices (PD.ses, NRI and NTI). All standardized effect sized indices (PD.ses, NRI and NTI) were calculated using a comparison with fixed-fixed null models, which maintain both species richness and species abundance across sites and tend to exhibit low type I and II error rates (see Miller et al., 2017). The null model matrices were randomized using the "independent-swap" algorithm by Gotelli (2000), which is well suited for presence/absence community matrices.

We studied the variation SR and PD.ses, NTI and NRI in a two-way ANOVA design considering Habitat and Succession as explanatory variables, also taking into account their interaction effect. We further explored the differences in the levels of the significant terms performing a Post-Hoc Tukey Test.

To assess the role of Junipers communis in the phylogenetic $\alpha$-diversity patterns found, we repeated the analyses on PD.ses, NTI and NRI excluding this species, and keeping the same design described above.

\section{Trends of compositional shifts $(\beta$-diversity)}

Peer) reviewing PDF | (2019:07:39774:3:0:NEW 28 Jan 2020) 
239 To assess the variations in species composition of plots, we ran a comparison among a detrended

240

241

242

243

244

245

246

247

248

249

250

251

252

253

254

255

256

257

258

259

260

261

262

263

264

265

266

267

268

269

270

271

272

273

274

275

276

277

278

correspondence analysis (DCA) and a canonical correspondences analysis (CCA) on the plot species composition. Thus, we checked the efficiency of constrained axis to catch the variation explained by unconstrained axis, as provided in the software Canoco 5 (ter Braak and Šmilauer 2012) and following Šmilauer and Lepš (2014). In DCA the axes were detrended by segment, adopting default options in Canoco 5 In the CCA, Habitat and Succession were used as explanatory variables and the significance of the constrained axes was tested with 4999 unrestricted permutations.

We used the methodological framework developed by Podani and Schmera (2011) to evaluate the trends in $\beta$-diversity components during the succession. This methodology allows the partition of pairwise gamma diversity into three complementary indices, measuring Similarity, relative Richness Difference and relative Species Replacement (respectively S, D and R), and accordingly is referred to as SDRSimplex approach (see also Appendix S2 for further description). Pairwise-comparisons regarded plots of the same habitat, spanning along the succession. The SDRSimplex results were projected in a ternary plot. Finally, we used a Nonparametric Kruskal-Wallis test to check the significance of the differences among habitats. To assess the role of particular species in the species turnover, we carried out an Indicator Species Analysis (ISA, Dufrêne and Legendre 1997). The ISA allows computing an indicator value $d$ (ranging between 0 and 100) of each species as the product of the relative frequency and relative average abundance of species in clusters. The analysis also produces a significance value, representing the probability of obtaining a $d$ value as high as that observed over 1000 iterations. We conducted the analyses considering each stage of succession of the two habitats as a separate cluster.

We used a three dimension Non-Metric Multidimensional Scaling (NMDS) ordination based on the UniFrac index distance matrix, to assess how different were the communities from the phylogenetic point of view. UniFrac is a phylogenetic diversity-based dissimilarity index that measures the proportion of evolutionary history unique to each community and is calculated as the total branch length unique to each community relative to the total branch length linking all species in both communities (Lozupone and Knight 2005).

Furthermore, we studied the evolutionary dissimilarity between communities along the succession (phylogenetic $\beta$-diversity), adopting the approach described in Leprieur et al. (2012) as an improvement of PhyloSor index. This index expresses to what extent the compared communities are composed by related species rather than by species that share no branch in the phylogeny and can be separated in two components accounting for 'true' phylogenetic turnover (PhyloSor $\left.{ }_{T u r n}\right)$ and phylogenetic diversity gradients $\left(\right.$ PhyloSor $\left._{\mathrm{PD}}\right)$. In addition, we also analyzed the standardized effect size of such indices (i.e. SES.PhyloSor, SES.PhyloSor ${ }_{\text {Turn }}$ and SES.PhyloSor ${ }_{\mathrm{PD}}$ ), which describe whether two communities are phylogenetically more or less dissimilar than what is expected given their taxa dissimilarity. These indices are obtained via comparison with a null model in which species are randomized across the tips from the tree while holding constant species richness and compositional beta diversity in 999 simulations.

Peer) reviewing PDF | (2019:07:39774:3:0:NEW 28 Jan 2020) 
279 Again, we used a Nonparametric Kruskal-Wallis test to check the significance of the differences

280 among the two habitat types.

281 Furthermore, to assess the role of Junipers communis in the phylogenetic $\beta$-diversity patterns

282 found, we repeated the analyses excluding this species, and keeping the same design described

283 above.

284 All ordination analyses (DCA, CCA and NMDS) and relative graphs were made using the

285 software Canoco 5 vers. 5.12 (ter Braak and Šmilauer 2012). All other analyses were made using

286 R software (version 3.5, The R Foundation for Statistical Computing, Vienna, Austria, www.R-

287 project.org), and relative graphs were produced with ggplot2 vers. 2.2.1 (Wickham 2009). The

288 ISA was conducted using the package labdsv (R package version 1.8-0, https://CRAN.R-

289 project.org/package=labdsv). Phylogenetic $\beta$-diversity indices were calculated exploiting the $\mathrm{R}$

290 functions developed by Leprieur et al. (2012). Phylogenetic $\alpha$-diversity metrics were obtained

291 with the package metricTester vers. 1.3.6 (Miller et al., 2017).

292

293 Results

294

295 The sampling resulted in 147 species (Table S2), with 69 shared species among the two habitats

296 and 39 species exclusive to each habitat (tot. 108 species in both habitats). Species richness

297 varied from 5 to 29 species per plot, in Abandoned dry grasslands and Managed dry grasslands,

298 respectively. The resulting phylogenetic tree is shown in Figure S1 (see Appendix S3 for the tree

299 in Newick format).

300 Species richness was comparable between the two habitats and decreased in both during the

301 succession (Table 1, Fig. 1A). Conversely, PD.ses differed significantly among the habitats, with

302 lower values in dry grasslands, and during the succession, with a decrease in the latter stage

303 (Table 1, Fig. 1B). Regarding NRI, the two habitats showed different trends during the

304 succession (significant interaction Succession $\mathrm{x}$ Habitat, Table 1). Indeed, while they displayed

305 comparable values at earlier succession stages with values indicating random processes of

306 species selection, dry grasslands shifted in the latter stage to a significant overdispersion of plant

307 composition, with the mean NRI value below the critical threshold of -1.96 and significantly

308 different from the one of hay meadows (Fig. 1C). On the other hand, the two habitats displayed a

309 comparable NTI trend during the succession, with values in hay meadows generally higher

310 (Succession and Habitat both significant, but no significant interaction, Table 1).

311 Notwithstanding a significant drop in the latter stages of succession, in all three stages the mean

312 NTI values remained between $+/-1.96$, again indicating random processes of species selection

313 (Fig. 1D).

314 The analyses concerning phylogenetic $\alpha$-diversity conduced excluding J. communis showed

315 quite a different scenario. PD.ses varied significantly between the two habitats and showed

316 different trends during the succession (Interaction term Succession $\mathrm{x}$ Habitat significant, see

317 Table 2), while both NTI and NRI varied significantly only along the succession with

318 comparable trends between the two habitats (Table 2). Indeed, we recorded a steep increase in 
319 PD.ses in abandoned dry grasslands compared to the values obtained considering J. communis. 320 As a result, PD.ses in dry grassland is more or less stable along the succession, while it varies 321 significantly in hay meadows (Fig 2A). On the contrary, phylogenetic overdispersion in dry 322 grasslands clearly vanished, with both NTI and NRI higher than those J. communis and even 323 closer to 0 than those of hay meadows, thus with a net predominance of random processes of 324 species selection (Fig 2 C, D).

325 The species composition of two habitats resulted clearly separated along the succession. CCA

326

327

328

329

330

331

332

333

334

335

336

337

338

339

340

341

342

343

344

345

346

347

348

349

350

351

352

353

354

355

356

357

358 constrained axes showed a very good efficiency, catching $85.5 \%$ and $100 \%$ of variation explained by DCA unconstrained axis. Total variation is 4.87, DCA first two axes explained $10.9 \%$ and $6.9 \%$ of it, while CCA ones $9.3 \%$ and $6.9 \%$ ( $<<0.001)$. Plots resulted clearly differentiated in terms of species composition with a clear set of taxa specific to each habitat and each stage, with changes during the succession lying on the horizontal axis and differences among the two habitats on the vertical one (see Fig $3 \mathrm{~A}$ and B). According to the ordinations, the two habitats show common trends of species replacement, with new species coming in the transition stage and a further differentiation in the last stage.

The pairwise comparisons across the two habitats highlighted significant differences in the trends in species turnover among the succession. Indeed, they shared consistently low values of similarity (S) but were characterized by significantly different values of species replacement (R) and richness difference (D). In particular, dry grasslands displayed a higher $\mathrm{D}$ and a lower $\mathrm{R}$ than hay meadows (Fig. 4).

The ISA confirmed the presence of different trends in the numbers of species characterizing the succession stages and leading the succession. In the managed stage, the two habitats shared the same number of indicator species, but hay meadows presented a higher number of indicators species than dry grasslands in the following stages $(17,5$, and 9 species in hay meadows vs. 17, 3 and 1 in dry grasslands in the Managed, Transitional and Abandoned stages, respectively, see table S3).

The NMDS ordination on phylogenetic distance among plot allowed a good representation of the UniFrac distances (Stress criterion $=0.141$ ). As for DCA and CCA, in the NMDS first axis reported the changes during the succession, while the habitat are separated along the second axis. Here, particularly the transitional stage of hay meadows show a high similarity with managed and transition stages of dry grasslands, while again the two habitats showed a relevant differentiation in the latter stage (Fig. 5).

Phylogenetic $\beta$-diversity was comparable among the two habitats and in both communities was mainly composed by phylogenetic turnover (Fig 6A). Only PhyloSorPD was significantly different between the two habitats, being higher in dry grasslands than in hay meadows. None of the phylogenetic $\beta$-diversity standardized metrics differed significantly from what is expected given the taxa dissimilarity (all values between $+/-1.96$, see fig 6C). Nevertheless, both SES.PhyloSor and the component SES.PhyloSorPD resulted significantly lower in dry grasslands than in hay meadows. The analyses conducted excluding $J$. communis from dry grasslands resulted in higher values of PhyloSor ${ }_{P D}$ and lower ones of PhyloSorPD, both differing 
359

360

361

362

363

364

365

366

367

368

369

370

371

372

373

374

375

376

377

378

379

380

381

382

383

384

385

386

387

388

389

390

391

392

393

394

395

396

397

398

significantly between the two habitats (fig 6B). SES.PhyloSor ${ }_{\text {Turn }}$ also showed significantly lower values in dry grasslands (fig 6D).

\section{Discussion}

The two habitats showed different features characterizing the changes in species composition during the succession, even if they displayed a comparable tendency in species richness loss. The trend in species loss has a long history of detection in the succession following the abandonment of secondary grasslands (Corazza et al. 2016; Csergő et al. 2013; Dengler et al. 2014; Janišová et al. 2011; Rocchini et al. 2006). Concerning Apennine hay meadows, Ubaldi (2003) reported that when agricultural activities are abandoned, soil water capacity and structure decreases.

Consequently, also hay production decreases and these areas are used as pastures. Meanwhile, trampling and grazing further reduce water capacity and fertility of soils, so that they become dry grasslands, more or less xerophilous depending on the site. However, this general trend is not consistent with our findings, which highlighted a clear divergence of the two habitats during the succession.

The values of PD.ses showed that whether in managed and transition stages the PD is substantially consistent to what should be expected given the taxa richness, in the abandoned ones PD values were higher than expected. This indicate that whether SR decreased, PD do not decreased consistently, because the loss in species seems to be counterweighted by the presence of species with long branches in the phylogeny (and this is particularly true for dry grasslands). Regarding phylogenetic structure, we detected for the first succession stages a predominant role of random processes of species loss in both habitats. These trends may be consistent with a framework in which a random phylogenetic structure of the community is the result of competitive exclusion of species in the case of convergent traits (see Davies 2006). Nevertheless, we detected a net difference of the community structure concerning the deep nodes of phylogeny, linked to the overdispersion in the dry grasslands. This is the result of the reduction of the number of species and the appearance (as a dominant participant) of the stress-tolerant species J. communis (Pierce et al. 2017). This is in strong agreement with our hypothesis that these environments are dominated by a strong component of ecological stress. Accordingly, species assembling processes may have selected for traits allowing to survive in xeric environments (i.e. traits linked to conservative economics in the leaf economics spectrum, such as small and thick leaves, low growth rate, small specific leaf area and high leaf dry matter content), that in this case were shared between species distant in the phylogeny.

The analysis of $\beta$-diversity trends confirmed these differences. In both habitats, we evidenced a strong loss in species, but with a high component of richness difference in dry grasslands, indicating a smaller replacement by new species. These findings match with those of several authors, who showed how short species are outcompeted by dominant tall grasses in the first succession stages after the abandonment (Corazza et al. 2016), leading, in agreement with Grime (2001), to the exclusion of subordinate and accidental species. Furthermore, in the latter 
399

400

401

402

403

404

405

406

407

408

409

410

411

412

413

414

415

416

417

418

419

420

421

422

423

424

425

426

427

428

429

430

431

432

433

434

435

436

437

succession stages many more species are lost from the community with the dominance of $J$. communis. Also in hay meadows, the loss in species following the abandonment was characterized by a suppression of species, but with a major turnover of species. Accordingly, Csergö et al. (2013) demonstrated that the loss in species following the meadows abandonment may be driven by the suppression of dominant grasses by tall forbs, in meadows co-dominated by competitive stress-tolerant ruderals, whereas in meadows dominated by a single stresstolerant competitor, diversity loss resulted from increased abundance and biomass of the dominant grass.

These trends were confirmed by ISA results, which are consistent with the scenario outlined in the DCA and CCA scatterplots. The higher rate of richness difference, and the lower species replacement of dry grasslands, in particular emerged from the low number of species characterizing transition and abandoned stages. Indeed, in the managed stage, indicator species resulted numerically comparable among the two habitats. In managed hay meadows, the indicator species belong mainly to the families Poaceae and Fabaceae (Lolium perenne, Phleum bertolonii, Bromus hordeaceus, Cynosurus cristatus, Trifolium pratense, Vicia sativa and Lathyrus pratensis), strictly linked to the pastoral activities, or consisted of other mesotrophic plants favored by grazing (i.e. Ranunculus bulbosus). On the other hand, the indicator species of managed dry grasslands were more typical of shallow and rocky soils, such as Thymus longicaulis, Acinos alpinus, Trifolium scabrum, Bupleurum baldense and Cerastium brachypetalum. In the Transition, hay meadows were characterized by a higher number of indicator species, with species typical of open habitats (Centaurea nigrescens, Achillea collina, Poa trivialis, Dactylis glomerata, Cirsium tenoreanum). These features are consistent with the scenario described above following Csergő et al. (2013). Transition dry grasslands were characterized by the dominance of Brachypodium rupestre, (together with plants considered precursory of more closed and woody habitats, see e.g. Assini et al. 2014). The dominance of Brachypodium spp. in successions post-abandonment is a general trend widely demonstrated for Apennine grasslands (Corazza et al. 2016). Finally, J. communis resulted the sole indicator species of the abandoned dry grasslands, while abandoned hay meadows were characterized by a high number of indicator species, spanning from various woody species of several families (i.e. Rosaceae, Salicaceae, Aceraceae, Oleaceae) to some herbaceous plants (for example Ranunculus lanuginosus and Valeriana officinalis).

The analysis of phylogenetic distances among plots highlighted that while the two habitats were well differentiated in their managed stages (in term of species lineages), a certain degree of phylogenetic similarity could be observed between transition hay meadows and both managed and transition dry grassland, due to the replacement of lineages along the succession. Nevertheless, as the succession proceeded further, the species composition of abandoned grasslands led to a net differentiation of the two habitats. Indeed, the two habitats hosted some species in common (or at least some species sharing common lineages) in the transitional stage (as also highlighted by the CCA). Subsequently they differentiated again in the last stage, with a 
438 higher replacement in hay meadows and dry grassland more or less dominated by a specie $(J$. 439 communis) not present in hay meadows and phylogenetically distant from all other species.

440 As to phylogenetic $\beta$-diversity, both habitats showed a greater contribution of 'true' phylogenetic 441 turnover (reflected in a minor importance of phylogenetic gradient). These results indicated that 442 the difference among plots was due to the replacement of species coming from different lineages, 443 rather than from a simple difference in PD. Nevertheless, in both the cases of the simple and the

444

445

446

447

448

449

450

451

452

453

454

455

456

457

458

459

460

461

462

463

464

465

466

467

468

469

470

471

472

473

474

\section{Conclusions}

476 standardized indices, we recorded differences concerning the amount of beta diversity deriving simply from a difference in PD. This component is numerically higher in dry grasslands (referring to simple Phylosor.PD) but is lower than what could be expected given the taxa dissimilarities when looking at the SES.Philosor ${ }_{\mathrm{PD}}$. We can hypothesize that this dependence may be related to the presence in dry grasslands of lower species replacement, with the entrance of a species phylogenetically very distant from the others (J. communis), which balances out the importance of simple PD component.

The pivotal role of $J$. communis in dry grasslands emerged on re-running all analyses concerning phylogenetic $\alpha$ - and $\beta$-diversity excluding this species. This species resulted responsible for a high amount of PD.ses in dry grasslands, and also the main one responsible for the presence of patterns of overdispersion. Also looking at -diversity, once the balancing effect exerted by $J$. communis had been removed, the PhyloSor ${ }_{\mathrm{PD}}$ resulted even higher. In addition, the SES.PhiloSor component rose significantly, showing that the amount of SES.PhiloSor PD $_{\text {was substantially }}$ consistent to what could be expected given the taxa dissimilarities and is higher than the one observed in hay meadows. In addition, differences among the two habitats in both PhyloSor ${ }_{\text {Turn }}$ and SES.PhyloSor ${ }_{\text {Turn }}$ became significant when excluding J. communis, indicating firstly a lower replacement of lineages in dry grasslands, balanced by the bigger contribution of PhyloSor ${ }_{\mathrm{PD}}$ and secondly that replacement in dry grasslands was driven by species sharing a closer lineage than those in hay meadows. These results highlighted the important role of J. communis and pinpointed the importance of including this species in the analyses, also considering that this is a key species in late succession stages of dry grasslands, being the dominant one, but also that its presence may hide phylogenetic differences between habitats driven by other clades. It is also noteworthy that, whereas it is common to remove highly phylogenetic distinct species from phylogenetic analysis, this practice may lead to a partial understanding of the processes at work, and that an in-depth interpretation of phylogenetic patterns should be made both using or not this distantly related species.

In this study, we used presence/absence data, and it should be acknowledged that abundance data may have led to significantly divergent results. Even if in our case, one of the main species responsible for the recorded patterns was a very abundant and dominant one. Nevertheless, further studies including abundance data are necessary to better depict the processes at work. 
477 In conclusion, our data elucidate the differences in the secondary succession of dry grasslands

478 and hay meadows in the Tuscan Apennines. In both cases, we recorded a drop in taxonomic $\alpha-$

479 diversity during the succession, but the analyses of taxonomic $\beta$-diversity highlighted quite

480 different compositional changes, with dry grasslands mainly dominated by richness difference

481 and hay meadows characterized by higher species replacement. As regards the phylogenetic

482 patterns, we were able to verify that they followed a comparable trend in the earlier succession

483 stages of the two habitats, but the entrance of a single species characterized by a deep separation

484 in the phylogeny of the communities (i.e. J. communis) raises substantial differences. We

485 propose an important role of the ecological factors in these trends, with the selection of $J$.

486 communis fostered by a dominance of abiotic filters and resulting in the outcompeting of

487 subordinate and accidental species in the latter stage of the habitat succession in dry grasslands,

488 after an initial dominance of competitive exclusion of the species. Nevertheless, as noted in the

489 introduction, the assessment of links among phylogenetic patterns and ecological processes

490 needs more in-depth study. Our proposed scenario could be appropriate in the case of traits not

491 conserved in the phylogeny (and this could be in accordance with the idea that trait

492 conservativism should not be taken for granted, see Gerhold et al. 2015), but a certain evaluation

493 of plant traits is necessary to further explore such trends, especially considering the concerns

494 related to the use of phylogeny as proxies for community assembly mechanisms.

495

496

497

498

499

500

501

502

503

504

505

506

507

508

509

510

511

512

513

514

515

\section{Acknowledgements}

We wish to thank the Raggruppamento Carabinieri Biodiversità of the Reparto Carabinieri Biodiversità Pieve Santo Stefano, for its support. We also wish to thank the Editor Cajo ter Braak, Lars Götzenberger and one anonymous reviewer whose suggestions greatly helped improve the manuscript.

\section{References}

Allegrezza M, Biondi E (2011) Syntaxonomic revision of the Arrhenatherum elatius grasslands of central Italy. Fitosociologia 48(1):23-40.

Assini S, Filipponi F, Brusoni M, Zucca F (2014) Vegetation of abandoned areas in the northern Apennines (Italy): phytosociological aspects and biodiversity analysis. Botany Letters 161:379-393.

Biondi E, Allegrezza M, Guitian J (1988) Mantelli di vegetazione nel piano collinare dell'Appennino centrale. Doc Phytosoc n.s. 11:479-490.

Biondi E, Ballelli S, Allegrezza M, Zuccarello V (1995) La vegetazione dell'ordine Brometalia erecti Br.-Bl. 1936 nell'Appennino (Italia). Fitosociologia 30:3-45.

Bracchetti L, Carotenuto L, Catorci A (2012) Land-cover changes in a remote area of central Apennines (Italy) and management directions. Landscape and Urban Planning 104:157-70. 
516 Carmignani L, Conti P, Cornamusini, GPirro, A, (2013). Geological map of Tuscany (Italy).

517 Journal of Maps 9:487-497.

518 Chase JM, Myers JA (2011) Disentangling the importance of ecological niches from stochastic

519 processes across scales. Philosophical Transactions of the Royal Society B: Biological

520 Sciences 366:2351-2363.

521 Coppi A, Mengoni A, Selvi F (2008) AFLP fingerprinting of taxa of Anchusa endemic to the

522 Corso-Sardinian system: genetic diversity and differentiation of an insular endemic group

523 threatened with extinction. Biological Conservation 141:2000-2011.

524 Corazza M, Tardella FM, Ferrari C, Catorci A (2016) Tall grass invasion after grassland

525

526

527

528

529

530

531

532

533

534

535

536

537

538

539

540

541

542

543

544

545

546

547

548

549

550

551

552

553

554

555 abandonment influences the availability of palatable plants for wild herbivores: insight into the conservation of the Apennine chamois Rupicapra pyrenaica ornata. Environmental Management 57:1247-1261.

Csergő AM, Demeter L, Turkington R (2013) Declining Diversity in Abandoned Grasslands of the Carpathian Mountains: Do Dominant Species Matter? PLoS One 8:e73533.

Dengler J, Janisová M, Török P, Wellstein C (2014) Biodiversity of Palaearctic grasslands: a synthesis. Agriculture, Ecosystems \& Environment 182:1-14

Dufrêne M, Legendre P (1997) Species assemblages and indicator species: the need for a flexible asymmetrical approach. Ecology Monographs 67:345-366.

Erickson DL, Jones FA, Swenson NG, Pei N, Bourg NA, Chen W, Davies SJ, Ge X, Hao Z, Howe RW, Huang C-L, Larson AJ, Lum SKY, Lutz JA, Ma K, Meegaskumbura M, Mi X, Parker JD, Fang-Sun I, Wright SJ, Wolf AT, Ye W, Xing D, Zimmerman JK, Kress WJ (2014) Comparative evolutionary diversity and phylogenetic structure across multiple forest dynamics plots: a mega-phylogeny approach. Frontiers in Genetics 5:5 - 358.

Faith DP (1992) Conservation evaluation and phylogenetic diversity. Biological Conservation 61:1-10.

Feliner GN, Rosselló J (2007) Better the devil you know? Guidelines for insightful utilization of nrDNA ITS in species-level evolutionary studies in plants. Molecular Phylogenetics and Evolution 44:911-919.

Gerhold P, Cahill JF, Winter M, Bartish IV, Prinzing A (2015) Phylogenetic patterns are not proxies of community assembly mechanisms (they are far better). Functional Ecology 29(5):600-614.

Gotelli NJ (2000) Null model analysis of species co-occurrence patterns. Ecology 81(9):26062621.

Grime JP (2001) Plant Strategies, Vegetation Processes, and Ecosystem Properties. New York, USA: Wiley.

Hollingsworth PM, Graham SW, Little DP (2011) Choosing and Using a Plant DNA Barcode. PLoS One 6:e19254.

Janišová M, Bartha S, Kiehl K, Dengler J (2011) Advances in the conservation of dry grasslands - introduction to contributions from the 7th European Dry Grassland Meeting. Plant Biosystem 145:507-513. 
556 Katoh K, Standley DM (2013) MAFFT Multiple Sequence Alignment Software Version 7:

557

558

559

560

561

562

563

564

565

566

567

568

569

570

571

572

573

574

575

576

577

578

579

580

581

582

583

584

585

586

587

588

589

590

591

592

593

594

595

Improvements in Performance and Usability. Molecular Biology and Evolution 30:772-780

Kembel SW (2009) Disentangling niche and neutral influences on community assembly: assessing the performance of community phylogenetic structure tests. Ecology Letters, 12:949-960. https://doi.org/10.1111/j.1461-0248.2009.01354.x

Kraft NJ, Adler PB, Godoy O, James EC, Fuller S, Levine JM (2015) Community assembly, coexistence and the environmental filtering metaphor. Functional Ecology 29(5):592-599.

Leprieur F, Albouy C, De Bortoli J, Cowman PF, Bellwood DR, Mouillot D (2012) Quantifying phylogenetic beta diversity: distinguishing between 'true' turnover of lineages and phylogenetic diversity gradients. PLoS One 7:e42760.

Lepš J (1999) Nutrient status, disturbance and competition: an experimental test of relationships in a wet meadow. Journal of Vegetation Science 10:219-230.

Li DZ, Gao LM, Li HT, Wang H, Ge XJ, Liu JQ, Chen ZD, Zhou SL, Chen SL, Yang JB, Fu CX, Zeng CX, Yan HF, Zhu YJ, Sun YS, Chen SY, Zhao L, Wang K, Yang T, Duan GW (2011) Comparative analysis of a large dataset indicates that internal transcribed spacer (ITS) should be incorporated into the core barcode for seed plants. Proceedings of the National Academy of Sciences 108:19641-19646

Lozupone C, Knight R (2005). UniFrac: a new phylogenetic method for comparing microbial communities. Applied and Environmental Microbiology 71(12):8228-8235.

Magallón S, Gómez-Acevedo S, Sánchez-Reyes LL, Hernández-Hernández T (2015) A metacalibrated time-tree documents the early rise of flowering plant phylogenetic diversity. New Phytologist 207:437-453.

Miller ET, Farine DR, Trisos CH (2017) Phylogenetic community structure metrics and null models: a review with new methods and software. Ecography 40:461-477.

Monteiro AT, Fava F, Hiltbrunner E, Della Marianna G, Bocchi S (2011) Assessment of land cover changes and spatial drivers behind loss of permanent meadows in the lowlands of Italian Alps. Landscape and Urban Planning 100, :287-294.

Paradis E, Claude J, Strimmer K (2004) APE: analyses of phylogenetics and evolution in R language. Bioinformatics 20:289-290.

Pavoine S, Gasc A, Bonsall MB, Mason NW (2013) Correlations between phylogenetic and functional diversity: mathematical artefacts or true ecological and evolutionary processes? Journal of Vegetation Science 24:781-793.

Peco B, Carmona CP, de Pablos I, Azcárate FM (2012) Effects of grazing abandonment on functional and taxonomic diversity of Mediterranean grasslands. Agriculture, Ecosystems \& Environment 152:27-32.

Peco B, Sánchez AM, Azcárate FM (2006) Abandonment in grazing systems: consequences for vegetation and soil. Agriculture, Ecosystems \& Environment 113:284-294.

Pesaresi S, Biondi E, Casavecchia S (2017) Bioclimates of Italy. Journal of Maps 13:955-960

Pierce S, Negreiros D, Cerabolini BEL, Kattge J, Díaz S, Kleyer M, Shipley B, Wright SJ, Soudzilovskaia NA, Onipchenko VG, van Bodegom PM, Frenette-Dussault C, Weiher E,

Peer) reviewing PDF | (2019:07:39774:3:0:NEW 28 Jan 2020) 
596

597

598

599

600

601

602

603

604

605

606

607

608

609

610

611

612

613

614

615

616

617

618

619

620

621

622

623

624

625

626

627

628

629

630

631

632

633

634

635

Pinho BX, Cornelissen JHC, Grime JP, Thompson K, Hunt R, Wilson PJ, Buffa G, Nyakunga OC, Reich PB, Caccianiga M, Mangili F, Ceriani RM, Luzzaro A, Brusa G, Siefert A, Barbosa NPU, Chapin FS, III Cornwell WK, Fang J, Fernandes GW, Garnier E, Le Stradic S, Peñuelas J, Melo FPL, Slaviero A, Tabarelli M, Tampucci D (2017) A global method for calculating plant CSR ecological strategies applied across biomes world-wide. Functional Ecology 31:444-457.

Podani J, Schmera D (2011) A new conceptual and methodological framework for exploring and explaining pattern in presence-absence data. Oikos 120:1625-1638.

Poldini L, Vidali M, Zanatta K (2002) La classe Rhamno-Prunetea in Friuli Venezia Giulia e territori limitrofi. Fitosociologia 39(Suppl. 2):29-56

Prinzing A (2016) On the opportunity of using phylogenetic information to ask evolutionary questions in functional community ecology. Folia Geobotanica, 51(1):69-74.

Purschke O, Schmid BC, Sykes MT, Poschlod P, Michalski SG, Durka W, Kühn I, Winter M, Prentice HC (2013) Contrasting changes in taxonomic, phylogenetic and functional diversity during a long-term succession: insights into assembly processes. Journal of Ecology 101(4):857-866.

Qian H, Hao Z, Zhang J (2014) Phylogenetic structure and phylogenetic diversity of angiosperm assemblages in forests along an elevational gradient in Changbaishan, China. Journal of Plant Ecology, 7(2), 154-165.

Rocchini D, Perry GLW, Salerno M, Maccherini S, Chiarucci A (2006) Landscape change and the dynamics of open formations in a natural reserve. Landscape and Urban Planning $77: 167-77$

Sandel B (2018) Richness-dependence of phylogenetic diversity indices. Ecography 41:837-844 Selvi F, Carrari E, Coppi A (2016). Impact of pine invasion on the taxonomic and phylogenetic diversity of a relict Mediterranean forest ecosystem. Forest Ecology and Managment 367:111 .

Slik JWF, Franklin J, Arroyo-Rodríguez V, Field R, Aguilar S, Aguirre N, Ahumada J, Aiba SI, Alves LF, K A, Avella A, Mora F, Aymard C GA, Báez S, Balvanera P, Bastian ML, Bastin JF, Bellingham PJ, van den Berg E, da Conceição Bispo P, Boeckx P, Boehning-Gaese K, Bongers F, Boyle B, Brambach F, Brearley FQ, Brown S, Chai SL, Chazdon RL, Chen S, Chhang P, Chuyong G, Ewango C, Coronado IM, Cristóbal-Azkarate J, Culmsee H, Damas K, Dattaraja HS, Davidar P, DeWalt SJ, Din H, Drake DR, Duque A, Durigan G, Eichhorn K, Eler ES, Enoki T, Ensslin A, Fandohan AB, Farwig N, Feeley KJ, Fischer M, Forshed O, Garcia QS, Garkoti SC, Gillespie TW, Gillet JF, Gonmadje C, Granzow-de la Cerda I, Griffith DM, Grogan J, Hakeem KR, Harris DJ, Harrison RD, Hector A, Hemp A, Homeier J, Hussain MS, Ibarra-Manríquez G, Hanum IF, Imai N, Jansen PA, Joly CA, Joseph S, Kartawinata K, Kearsley E, Kelly DL, Kessler M, Killeen TJ, Kooyman RM, Laumonier Y, Laurance SG, Laurance WF, Lawes MJ, Letcher SG, Lindsell J, Lovett J, Lozada J, Lu X, Lykke AM, Mahmud KB, Mahayani NPD, Mansor A, Marshall AR, Martin EH, Calderado Leal Matos D, Meave JA, Melo FPL, Mendoza ZHA, Metali F, Medjibe VP, Metzger JP, 
636

637

638

639

640

641

642

643

644

645

646

647

648

649

650

651

652

653

654

655

656

657

658

659

660

661

662

663

664

665

666

667

668

669

670

671

672

673

674

Metzker T, Mohandass D, Munguía-Rosas MA, Muñoz R, Nurtjahy E, de Oliveira EL, Onrizal, Parolin P, Parren M, Parthasarathy N, Paudel E, Perez R, Pérez-García EA, Pommer U, Poorter L, Qie L, Piedade MTF, Pinto JRR, Poulsen AD, Poulsen JR, Powers JS, Prasad RC, Puyravaud JP, Rangel O, Reitsma J, Rocha DSB, Rolim S, Rovero F, Rozak A, Ruokolainen K, Rutishauser E, Rutten G, Mohd Said MN, Saiter FZ, Saner P, Santos B, Dos Santos JR, Sarker SK, Schmitt CB, Schoengart J, Schulze M, Sheil D, Sist P, Souza AF, Spironello WR, Sposito T, Steinmetz R, Stevart T, Suganuma MS, Sukri R, Sultana A, Sukumar R, Sunderland T, Supriyadi, Suresh HS, Suzuki E, Tabarelli M, Tang J, Tanner EVJ, Targhetta N, Theilade I, Thomas D, Timberlake J, de Morisson Valeriano M, van Valkenburg J, Van Do T, Van Sam H, Vandermeer JH, Verbeeck H, Vetaas OR, Adekunle V, Vieira SA, Webb CO, Webb EL, Whitfeld T, Wich S, Williams J, Wiser S, Wittmann F, Yang X, Adou Yao CY, Yap SL, Zahawi RA, Zakaria R, Zang R (2018) Phylogenetic classification of the world's tropical forests. Proceedings of the National Academy of Sciences 115:1837-42

Šmilauer P, Lepš J (2014). Multivariate Analysis of Ecological Data using CANOCO 5. Cambridge: Cambridge University Press. doi:10.1017/CBO9781139627061

Stamatakis A (2006) RAxML-VI-HPC: maximum likelihood-based phylogenetic analyses with thousands of taxa and mixed models. Bioinformatics 22:2688-2690.

Swenson NG (2014) Functional and phylogenetic ecology in R. New York, USA: Springer. ter Braak CJF, Šmilauer P (2012). Canoco reference manual and user's guide: software for ordination, version 5.0. Ithaca USA: Microcomputer Power.

Tucker CM, Cadotte MW, Carvalho SB, Davies TJ, Ferrier S, Fritz SA, Grenyer R, Helmus MR, Jin LS, Mooers AO, Pavoine S, Purschke O, Redding DW, Rosauer DF, Winter M, Mazel F (2017) A guide to phylogenetic metrics for conservation, community ecology and macroecology. Biological Reviews 92:698-715

Ubaldi D (2003) Flora, fitocenosi e ambiente. Elementi di Geobotanica e Fitosociologia. Bologna, IT: CLUEB.

Viciani D, Dell'Olmo L, Gabellini A, Gigante D, Lastrucci L (2018) Landscape dynamics of Mediterranean montane grasslands over 60 years and implications for habitats conservation. A case study in the northern Apennines (Italy). Landscape Research 43:952-964.

Webb CO (2000) Exploring the phylogenetic structure of ecological communities: an example for rain forest trees. The American Naturalist 156:145-155.

Webb CO, Ackerly DD, McPeek MA, Donoghue MJ (2002) Phylogenies and community ecology. Annual Review of Ecology, Evolution, and Systematics 33:475-505.

Wickam H (2009) ggplot2: Elegant Graphics for Data Analysis. New York, USA: SpringerVerlag.

Zanne AE, Tank DC, Cornwell WK, Eastman JM, Smith SA, FitzJohn RG, McGlinn DJ, O'Meara BC, Moles AT, Reich PB, Royer DL, Soltis DE, Stevens PF, Westoby M, Wright IJ, Aarssen L, Bertin RI, Calaminus A, Govaerts R, Hemmings F, Leishman MR, Oleksyn J, 
675 Soltis PS, Swenson NG, Warman L, Beaulieu JM (2014) Three keys to the radiation of 676 angiosperms into freezing environments. Nature 506(7486):89. 


\section{Table $\mathbf{1}$ (on next page)}

Analysis of variance table for the effect of Habitat and Succession on indexes of taxonomic and phylogenetic $\alpha$-diversity.

Species Richness (SR), Standardized Effect Size of Faith's Phylogenetic Diversity (PD.ses), Net Relatedness Index (NRI) and Nearest Taxon Index (NTI). Significance codes: P value $<0.001$ “***”; P value < 0.01 “**”; P value $<0.05$ “*”) 


\section{Table 1.}

2

\begin{tabular}{llccrrrrl}
\hline Response & Factors & Df & ResDf & Sum Sq & $\begin{array}{r}\text { F } \\
\text { Value }\end{array}$ & P value & \\
\hline \multirow{2}{*}{ SR } & Habitat & 1 & 54 & 22.82 & 2.067 & 0.156 & \\
& Succession & 2 & 54 & 1930.23 & 87.458 & $<0.001$ & $* * *$ \\
& Habitat: Succession & 2 & 54 & 54.03 & 2.448 & 0.096 & \\
\hline \multirow{2}{*}{ PD.ses } & Habitat & 1 & 54 & 9.49 & 8.34 & 0.006 & $* *$ \\
& Succession & 2 & 54 & 55.60 & 24.43 & $<0.001$ & $* * *$ \\
& Habitat: Succession & 2 & 54 & 1.87 & 0.83 & 0.440 & \\
\hline \multirow{2}{*}{ NRI } & Habitat & 1 & 54 & 21.33 & 17.77 & $<0.001$ & $* * *$ \\
& Succession & 2 & 54 & 50.27 & 21.33 & $<0.001$ & $* * *$ \\
& Habitat: Succession & 2 & 54 & 17.08 & 7.11 & 0.002 & $* *$ \\
\hline \multirow{2}{*}{ NTI } & Habitat & 1 & 54 & 3.16 & 2.92 & 0.093 & \\
& Succession & 2 & 54 & 48.82 & 21.19 & $<0.001$ & $* * *$ \\
& Habitat: Succession & 2 & 54 & 1.29 & 0.64 & 0.554 & \\
\hline
\end{tabular}

3 


\section{Table 2 (on next page)}

Analysis of variance table for the effect of Habitat and Succession on indexes of phylogenetic $\alpha$-diversity evaluated excluding from the analyses the species Juniperus communis.

Standardized Effect Size of Faith's Phylogenetic Diversity (PD.ses), Net Relatedness Index (NRI) and Nearest Taxon Index (NTI). Significance codes: P value $<0.001$ “***”; P value < 0.01 “**”; P value $<0.05$ “*”. 
1 Table 2.

2

\begin{tabular}{llccrrrl}
\hline Response & Factors & Df & ResDf & Sum Sq & F Value & P value & \\
\hline \multirow{3}{*}{ PD.ses } & Habitat & 1 & 54 & 0.50 & 0.58 & 0.451 & \\
& Succession & 2 & 54 & 28.29 & 16.30 & $<0.001$ & $* * *$ \\
& Habitat: Succession & 2 & 54 & 11.03 & 6.36 & 0.003 & $* *$ \\
\hline \multirow{3}{*}{ NRI } & Habitat & 1 & 54 & 0.39 & 2.05 & 0.158 & \\
& Succession & 2 & 54 & 7.33 & 19.03 & $<0.001$ & $* * *$ \\
& Habitat: Succession & 2 & 54 & 1.00 & 2.61 & 0.083 & \\
\hline \multirow{3}{*}{ NTI } & Habitat & 1 & 54 & 0.01 & 0.01 & 0.920 & \\
& Succession & 2 & 54 & 25.69 & 17.09 & $<0.001$ & $* * *$ \\
& Habitat: Succession & 2 & 54 & 4.18 & 2.78 & 0.071 & \\
\hline
\end{tabular}

3 
Figure 1

Interaction plots for the variation in taxonomic and phylogenetic $\alpha$-diversity of the 60 sampled plots according to Habitat and Succession.

(A) Species Richness (SR). (B) Standardized Effect Size of Faith's Phylogenetic Diversity (PD.ses). (C) Net Relatedness Index (NRI). (D) Nearest Taxon Index (NTI) Different letters indicate significant differences $(p<0.05)$ after a Post Hoc Tukey's test conducted in A, B and D) between the levels of the factor Succession, and in C) between the levels of the interaction Succession*Habitat, according to the ANOVA results.
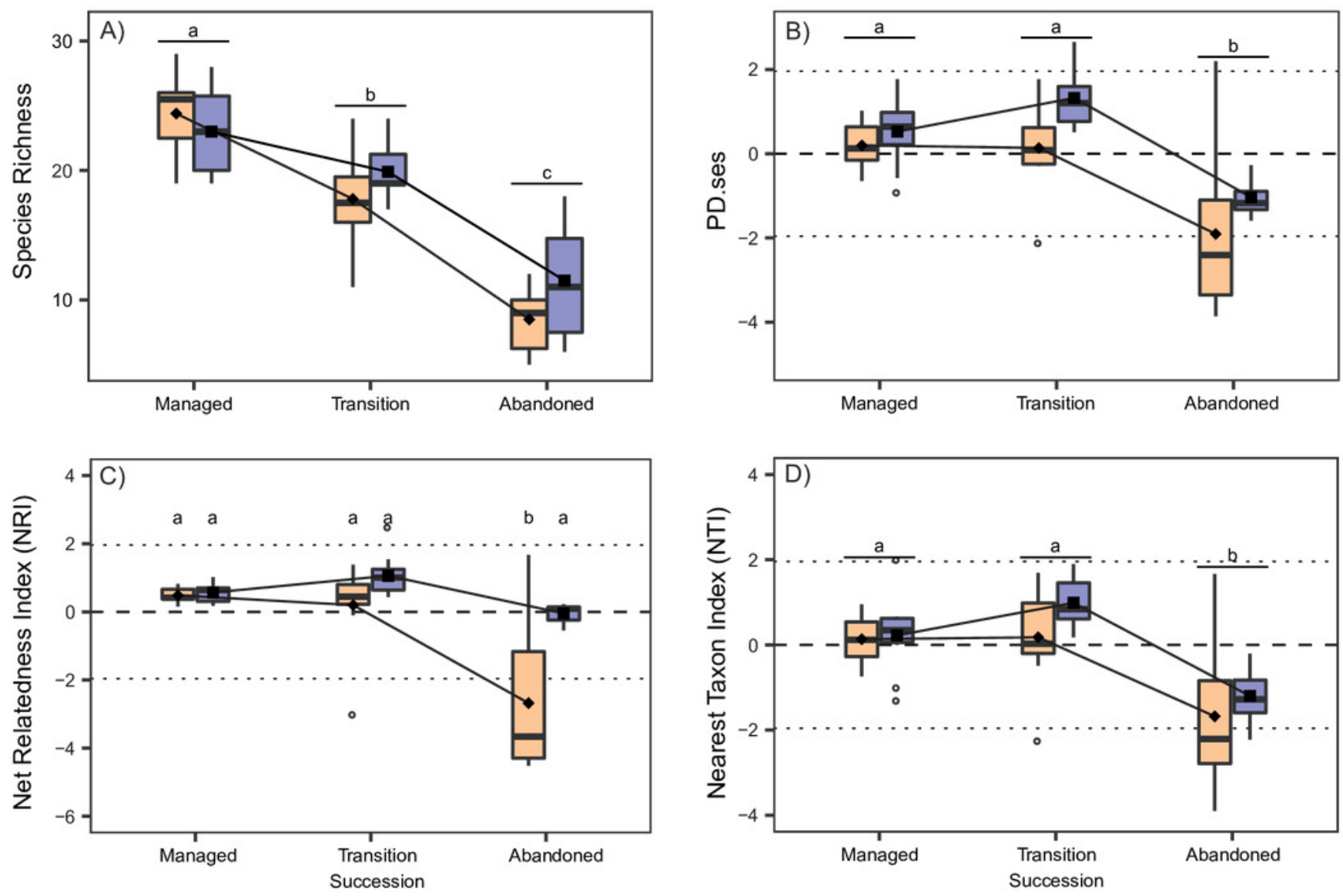

Dry_grasslands

Hay_meadows 
Figure 2

Interaction plots for the variation in phylogenetic $\alpha$-diversity of the 60 sampled plots according to Habitat and Succession evaluated excluding from the analyses the species Juniperus communis.

(A) Standardized Effect Size of Faith's Phylogenetic Diversity (PD.ses). (B) Net Relatedness Index (NRI). (C) Nearest Taxon Index (NTI). Different letters indicate significant differences $(p<0.05)$ after a Post Hoc Tukey's test conducted in A) between the levels of the interaction Succession*Habitat, and in B and C) between the levels of the factor Succession, according to the ANOVA results.
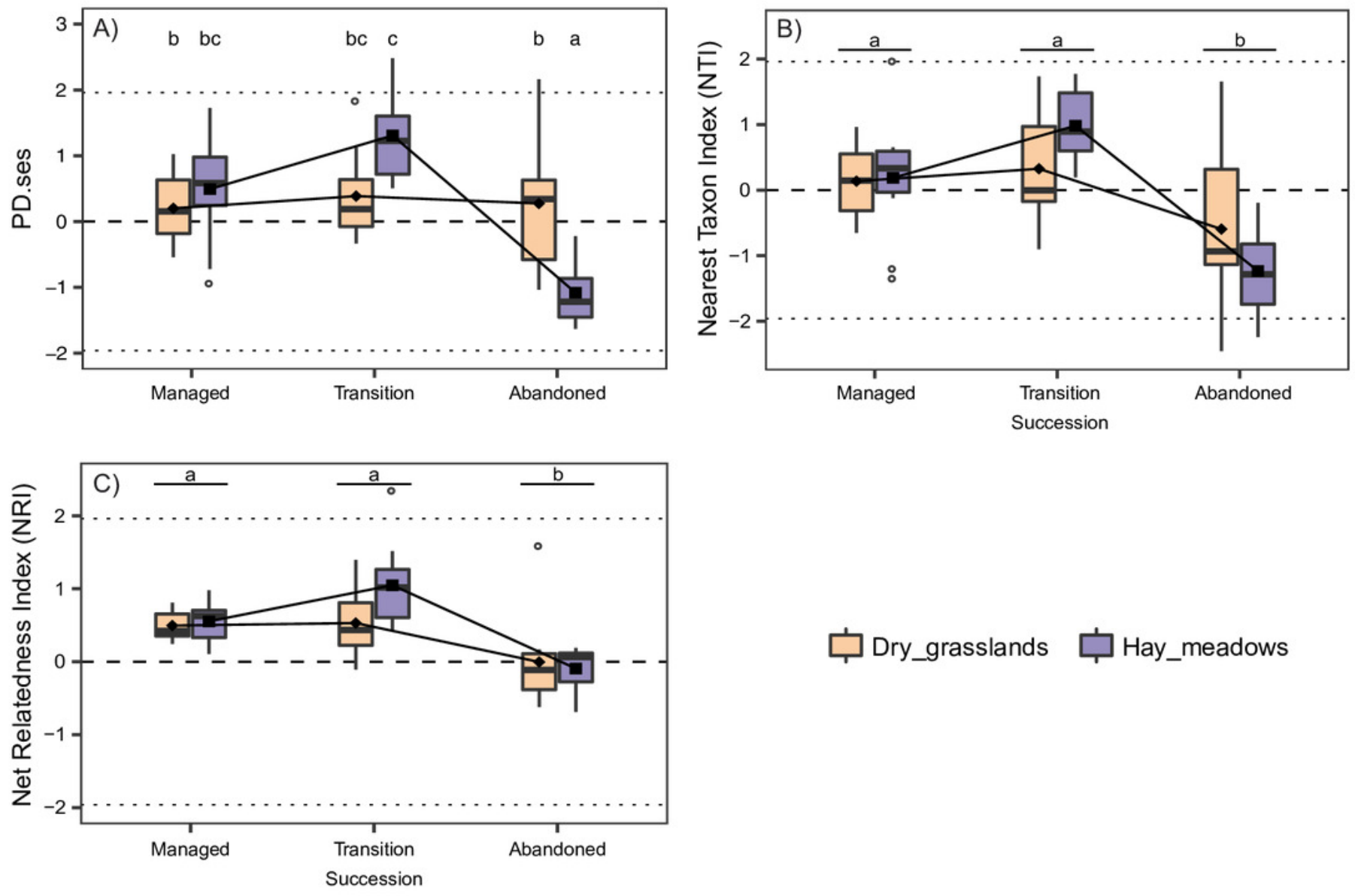

Dry_grasslands

Hay_meadows 


\section{Figure 3}

Ordination diagrams considering species composition of plots.

A) Plot distribution according to DCA considering their species composition. Empty symbols represent hay meadows and full symbols represent dry grasslands. Rhombus represent managed plots, circles transition plots and squares abandoned ones. B) Plant species distribution obtained with CCA, only 50 best fitting species are shown, see also table S3 for indicator species. Blue triangles represent the species. In both graphs, red triangles represent plot centroids according to Habitat type and Stage of Succession. H-MN= managed hay meadows, $\mathrm{H}-\mathrm{TR}=$ transition hay meadows, $\mathrm{H}-\mathrm{AB}=$ abandoned hay meadows, $\mathrm{D}-\mathrm{MN}=$ managed dry grasslands $D-T R=$ transition dry grasslands $D-A B=$ abandoned dry grasslands. 

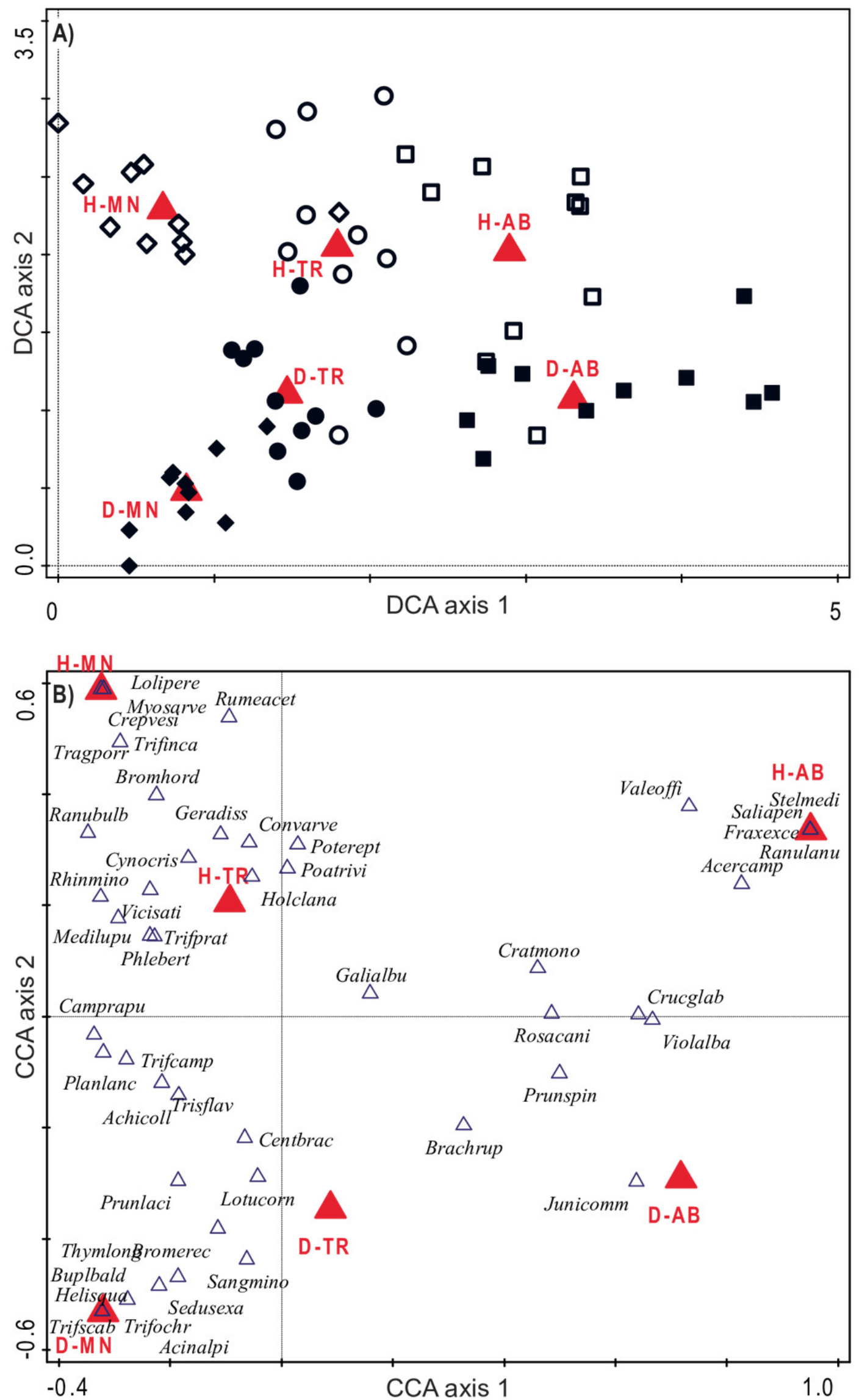
Figure 4

SDR simplex ternary plots showing the variation in taxonomic $\beta$-diversity along the seconadary succession of the two habitats.

(A) Dry grasslands. (B) Hay meadows. The abbreviations S, D and R refer to similarity, richness difference and species replacement, respectively. Mean values of $S, D$, and R are reported. Values marked with * are significantly different at $\mathrm{P}<0.05$ according to a KruskalWallis test performed between the two habitats.

A)

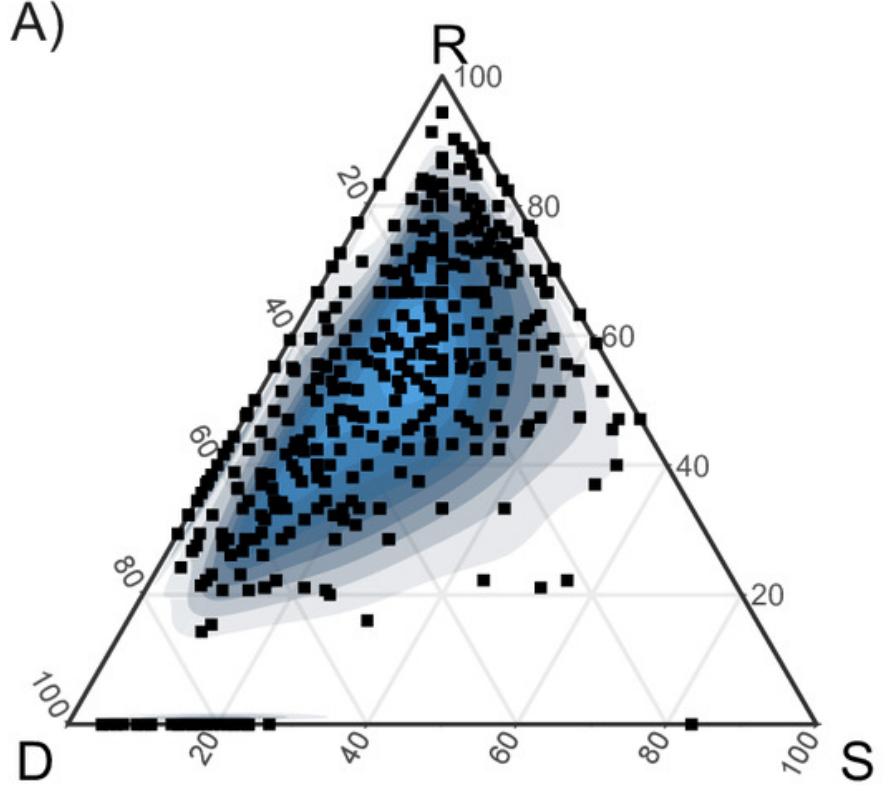

$R=49.98^{*}, D=33.95^{*}, S=16.06$
B)

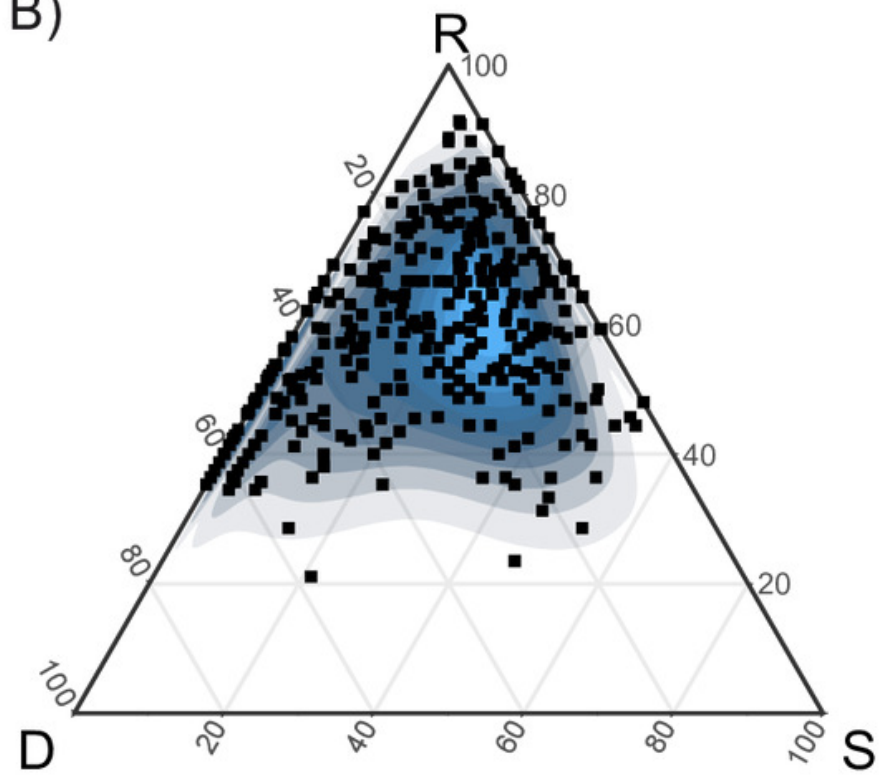

$R=60.16^{*}, \mathrm{D}=22.58^{*}, \mathrm{~S}=17.25$ 


\section{Figure 5}

Ordination diagram based on phylogenetic distance of plots.

Plot distribution according to NMDS ordination based on the UniFrac index distance matrix.

Empty symbols represent hay meadows and full symbols represent dry grasslands. Rhombus represent managed plots, circles transition plots and squares abandoned ones. Convex hull envelopes enclose plots according to Habitat type and Stage of Succession. H-MN= managed hay meadows, $\mathrm{H}-\mathrm{TR}=$ transition hay meadows, $\mathrm{H}-\mathrm{AB}=$ abandoned hay meadows, $\mathrm{D}-\mathrm{MN}=$ managed dry grasslands $D-T R=$ transition dry grasslands $D-A B=$ abandoned dry grasslands.

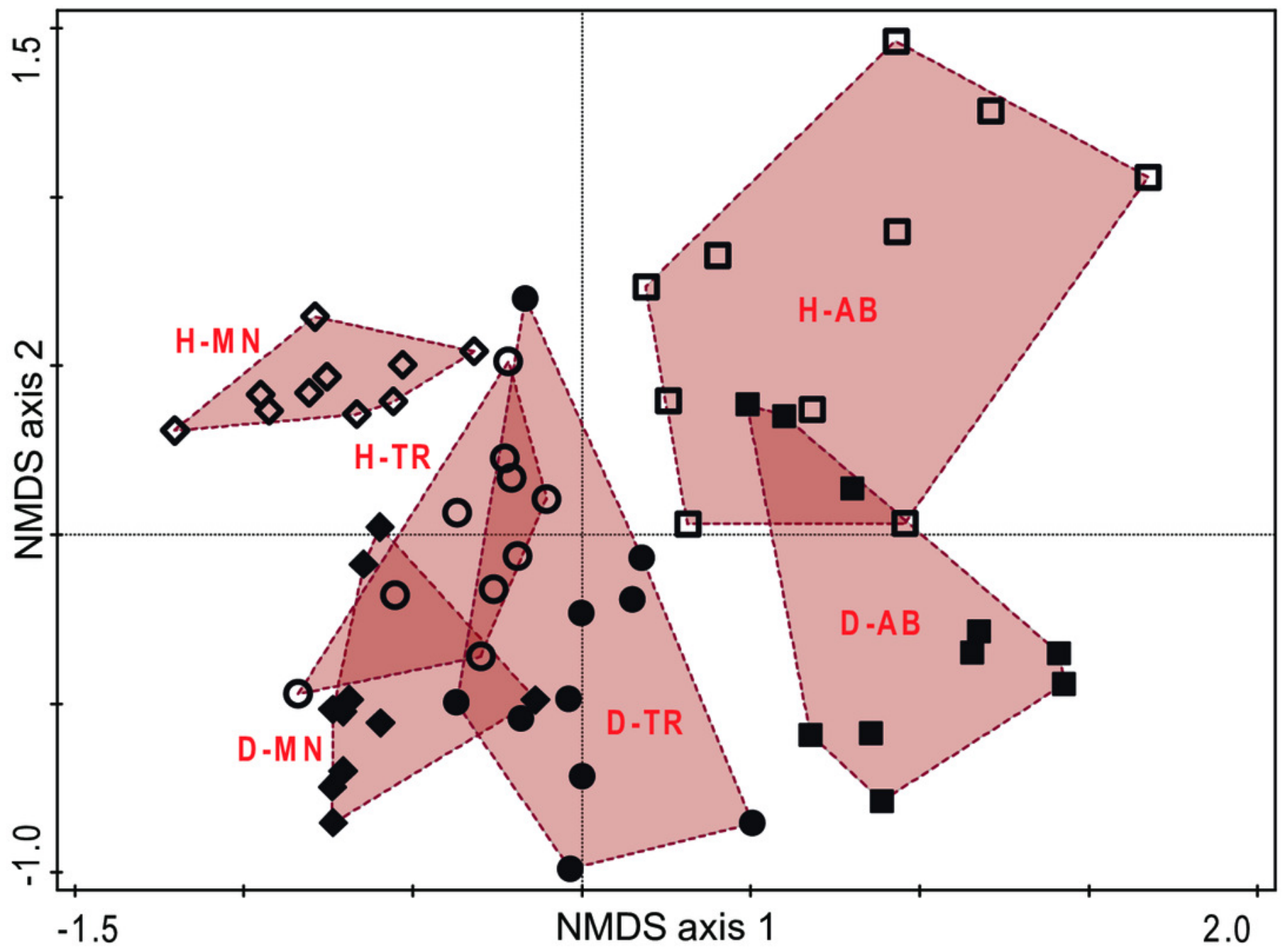




\section{Figure 6}

Boxplot graph for the variation in phylogenetic $\beta$-diversity according to Habitat and Succession for dry grasslands and hay meadows during the succession, evaluated with and without the species Juniperus communis.

A and B) PhyloSor index, and its two separate components accounting for 'true' phylogenetic turnover (PhyloSorTurn) and phylogenetic diversity gradients (PhyloSorPD) evaluated with and without the species J. communis, respectively; $C$ and D) their relative Standardized Effect Size (SES.PhyloSor, SES.PhyloSorTurn, SES.PhyloSorPD) again evaluated with and without the species J. communis, respectively. Couples of boxplot marked with * show data significantly different at $\mathrm{P}<0.05$ according to a Kruskal-Wallis test performed between the two habitats. 

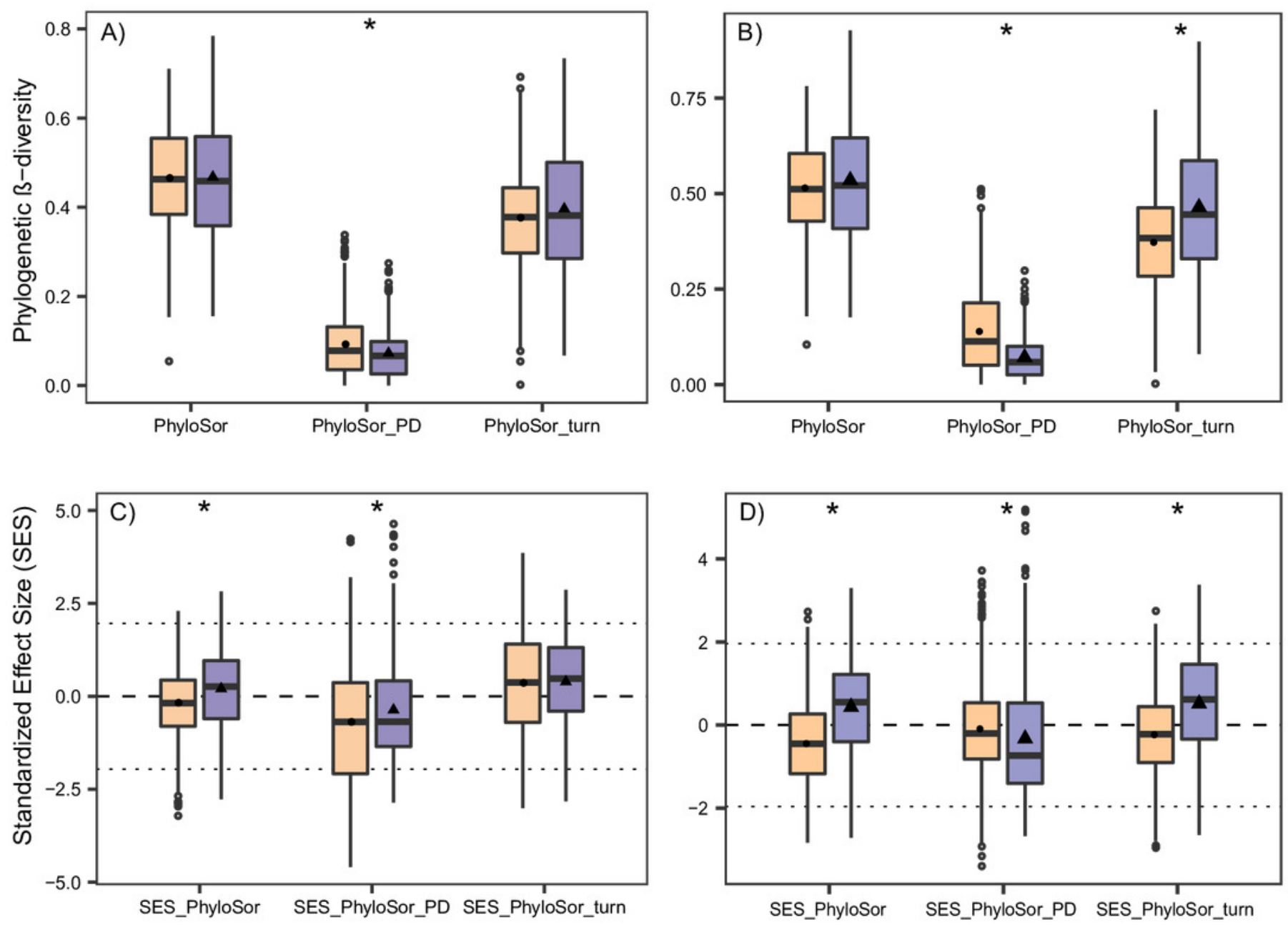

ウ Dry grasslands

Hay meadows 